\title{
Laitumen fosforikuormitus, tase ja pintavalunta
}

\author{
Kirsi Saarijärvi ja Perttu Virkajärvi \\ MTT, Pohjois-Savon tutkimusasema, Halolantie 31 A, 71750 Maaninka, kirsi.saarijarvi@mtt.fi, pert- \\ tu.virkajarvi@mtt.fi
}

\begin{abstract}
Johdanto
Suomen pintavesien rehevöitymisongelman tärkein syy on ulkoinen fosforikuormitus. Suomen järvet ovat melko matalia (keskisyvyys $6.9 \mathrm{~m}$ ), ja yleensä niissä on suljettuja lahtia ja poukamia, minkä vuoksi ne ovat erityisen alttiita rehevöitymiselle. Usein vesistöjen ympäristö on suotuisan maaperän takia maatalouskäytössä ja pelloilta pääsee helposti pintavalunnan mukana kulkeutumaan fosforia (P) vesistöihin. Ilmastotekijöistä eniten pintavalunnan määrään vaikuttaa roudan paksuus ja yhtenäisyys sekä lumen vesiarvo. Liukoinen ja partikkeleihin sitoutunut $\mathrm{P}$ huuhtoutuu vesistöihin erityisesti keväällä sulamisvesien mukana. Muuna aikana pintavalunta on vähäistä rankkoja sadekuuroja lukuun ottamatta. Peltoviljelyn aiheuttamaa P-kuormitusta on tutkittu (mm. Turtola 1999), mutta laitumilta tulevaa P-kuormitusta ei ole Suomessa mitattu. Syksyisen lietteen pintalevitys lisää seuraavan kevään P-huuhtoumaa, joten myös syksyisellä laidunnuksella voidaan olettaa olevan merkitystä. Laiduntaminen vaikuttaa maata tiivistävästi, mikä saattaa lisästä pintavalunnan määrää hienojakoisilla maalajeilla.
\end{abstract}

Pääosa pellolta huuhtoutuvasta fosforista kulkeutuu pintavalunnan mukana. Nurmiviljelyssä, erityisesti laiduntamisessa fosforia sitoutuu maan pintakerrokseen huomattavia määriä. Maan liukoisen fosforin pitoisuus ei kuitenkaan ole luotettava indikaattori huuhtoutumisalttiin fosforin arvioimiseen, sillä myös monet muut tekijät vaikuttavat fosforin huuhtoumiseen. Esimerkiksi maalaji, kaltevuus sekä maan fosforin sitomiskyky ovat tärkeitä. Uhlen (1988) listaa kolme tärkeintä talvialueilla nurmien fosforin huuhtoutumiseen vaikuttavaa tekijää: 1 . Lumen sulamisesta johtuvan pintavaluman määrä $\mathrm{mm}, 2$. Syksyllä maahan jäänyt kasvimassa ja sen P-pitoisuus, 3. Aiempi P-lannoitus. Jos maa on paljas, kalteva ja huonosti läpäisevä, suuri osa fosforista huuhtoutuu eroosion mukana partikkelimuodossa. Helposti läpäisevillä, kasvipeitteisillä mailla pääosa huuhtoutuvasta fosforista on liukoisessa muodossa (Turtola 1999). Kun sekä annettu että poistuva P-määrä tunnetaan, alueelle voidaan laskea P-tase. Laitumen P-taseeseen vaikuttavat lannoitus, laidunpaine, lehmien kivennäis- ja väkirehuruokinta ja maidon mukana poistunut P. Vaikka tase antaa kuvan fosforinkäytön tehokkuudesta, se on kuitenkin huono fosforin huuhtoutumisriskin estimaatti. P sitoutuu helposti maapartikkeleiden pinnalle ja on sitoutuneessa muodossa hyvin puskuroitu muutoksia vastaan (Uhlen 1988).

Tässä tutkimuksessa selvitettiin laitumen P-kuormitusta vakioidulla laidunpaineella ja laiduntamisen vaikutusta laitumen pintamaan P-pitoisuuteen sekä pintavalunnan määrään ja sen P-pitoisuuteen. Lisäksi esitetään arvio laitumen pintavalunnan vaikutuksesta erikokoisten järvien rehevöitymisriskiin.

\section{Aineisto ja menetelmät}

Koealue on MTT:n Pohjois-Savon tutkimusasemalle 1986 perustettu 0,7 ha kokoinen lysimetrikenttä. Kentän maaperä FAO-luokituksen mukaan Dystric Regosol, medium textured. Maan koostumus 60 cm syvyyteen on $43 \%$ hienoa hietaa, $21 \%$ karkeaa hietaa ja $7.0 \%$ savea. Kentällä on $12 \mathrm{kpl} 100 \mathrm{~m}^{2}$ lysimetriä sekä syksyllä 2000 rakennetut $2 \mathrm{kpl} 400 \mathrm{~m}^{2}$ pintakeräintä. Timotei-nurminatanurmi perustettiin koetta varten vuonna 2000. Kentän $\mathrm{P}$ lannoitus oli $26 \mathrm{~kg} \mathrm{P} \mathrm{ha}^{-1} \mathrm{v}^{-1}$ ja lehmien väki- ja kivennäisrehuissa lisäfosforia tuli $\mathrm{n} .10-12 \mathrm{~kg} \mathrm{P} \mathrm{ha}^{-1}$. Lehmien maitomäärä mitattiin laidunkierroksittain, samoin tarjolla olevan kasvuston P-pitoisuus.

Lysimetri- ja pintavalunnan määrä kirjattiin valumahuipun aikaan kolmesti vuorokaudessa ja muuna aikana kahdesti viikossa. Lysimetreistä otettiin kokoomavesinäytteet n. $500 \mathrm{~m}^{3} \mathrm{ha}^{-1}$ välein ja pintakeräimistä vastaavasti $\mathrm{n} .125 \mathrm{~m}^{3} \mathrm{ha}^{-1}$ välein. Vedestä määritettiin mm. totaali $\mathrm{P}, \mathrm{PO}_{4}-\mathrm{P}$ ja liukoinen $\mathrm{P}$. Koealueen maaperän P-pitoisuus määritettiin kokeen alussa ja aina laidunvuoden päätteeksi ennen maan routaantumista. Maaperän tiivistymistä on seurattu vuosittain penetrometrimittauksilla samassa yhteydessä. Kentältä mitattiin roudan syvyys talvisin kahden viikon välein ja sulamisaikaan päivittäin. Lumen maksimi vesiarvo mitattiin vuosittain. 


\section{Tulokset ja tulosten tarkastelu}

Fosforitase riippuu lannoituksesta ja laiduntamisen intensiteetistä. Kaksi kolmasosaa laitumen Pkuormituksesta oli lannoitefosforia ja yksi kolmasosa oli peräisin väkirehuista ja kivennäisistä (taulukko 1). Sontakasojen määrän ja sonnan P-pitoisuuden perusteella yli $16 \mathrm{~kg} \mathrm{P} \mathrm{ha}^{-1}$ kiersi systeemissä laidunkauden aikana. Tämä vastaa $46 \%$ alueelle annetusta kokonaisfosforista. Suurin P-nielu oli maito, joka muodosti $75 \%$ kokonaispoistumasta. Pintavalunnan merkitys oli vähäinen, keskimäärin $2.3 \%$ annetusta fosforista mikä vastaa $6 \%$ :a kokonaispoistumasta. Pohjaveteen fosforia huuhtoutui täysin merkityksetön määrä. Turtolan ja Kemppaisen (1998) hienolla hietamaalla tekemissä kokeissa NPKlannoituksen $\left(21.4 \mathrm{~kg} \mathrm{P} \mathrm{ha}^{-1}\right)$ sekä toukokuisen lietteen levityksen $\left(28.6 \mathrm{~kg} \mathrm{P} \mathrm{ha}^{-1}\right)$ jälkeen huuhtoutui alle $5 \%$ annetusta fosforista, mikä vastaa tämän kokeen tulosta. Sen sijaan syksyisen lietteenlevityksen $\left(28.2 \mathrm{~kg} \mathrm{P} \mathrm{ha}^{-1}\right)$ jälkeen huuhtoutui $11 \%$ annetusta fosforista.

Koska tässä kokeessa ei käytetty eri fosforitasoja, kokeen perusteella ei ole mahdollista arvioida taseen käyttökelpoisuutta fosforin huuhtoutumisriskin ennakointiin. Lisäksi fosforin kertyminen maahan vuosien mittaan tuottaa ongelmia taseen käyttämisessä huuhtoutumisriskin arviointiin. Jos maan fosforinsitomiskyky ylittyy jossain vaiheessa, seurauksen saattaa olla huuhtoutumispulssi, vaikka annettu Plannoitus olisi vuosittain vakio. Turtolan (1999) mukaan taseen ja sadon fosforipoistuman suhde (tase/maito) kuvaa pitkän aikavälin huuhtoutumisriskiä. Tässä kokeessa suhde on 2.1 mikä on korkeampi kuin Turtolan säilörehunurmella eri lannoitusvaihtoehdoilla saamat arvot (NPK 0,67; liete toukokuu 1,7 ; liete syyskuu 1,8). Pitkän aikavälin huuhtoutumisriski on siis laitumella jonkin verran korkeampi kuin säilörehunurmella. Suhdeluku kertoo systeemin tehokkuudesta, mutta ei huomio maalajin vaikutusta todelliseen huuhtoutumisalttiuteen. Esimerkiksi heikosti fosforia sitovan karkean hiedan huuhtoutumisalttius kasvaisi nopeammin kuin hienon hiedan, vaikka tase/sato-suhdeluku olisi kummallakin maalajilla sama.

Taulukko 1. Laitumelle annettu ja poistunut fosfori 2001-2003.

\begin{tabular}{|c|c|c|c|}
\hline & 2001 & 2002 & 2003 \\
\hline \multicolumn{4}{|l|}{ Annettu kg ha ${ }^{-1}$} \\
\hline Väkilannoite & 22.8 & 22.8 & 22.8 \\
\hline Väkirehu & 13.6 & 13.1 & 14.0 \\
\hline Yhteensä & 36.4 & 35.9 & 36.8 \\
\hline \multicolumn{4}{|l|}{ Poistunut kg ha ${ }^{-1}$} \\
\hline Maito & 10.5 & 9.6 & 11.7 \\
\hline Lypsyaikana eritetty & 2.7 & 2.6 & 2.8 \\
\hline Pohjavesivalunta & 0.011 & 0.017 & 0.022 \\
\hline Pintavalunta & 0.6 & 1.0 & 0.9 \\
\hline Yhteensä & 13.8 & 13.2 & 15.4 \\
\hline Tase $\mathrm{kg} \mathrm{ha}^{-1}$ & 22.6 & 22.7 & 21.4 \\
\hline Maan liukoisen P:n lisäys $(0-25 \mathrm{~cm}) \mathrm{kg} \mathrm{ha}^{-1}$ & 4.0 & 5.0 & na \\
\hline Maan sitoma $\mathrm{P} \mathrm{kg} \mathrm{ha}^{-1}$ (arvio) & 18.6 & 17.7 & \\
\hline
\end{tabular}

Laiduntaminen nosti selvästi maan pintakerroksen P-pitoisuutta (kuva 1). Vaikka 0-2 cm kerroksen liukoisen P:n pitoisuus oli syksyllä 2002 lähes kaksinkertaistunut lähtötilanteeseen verrattuna, nousu vastaa kuitenkin vain $\mathrm{n} .1 \mathrm{~kg}$ viljavuus-P ha ${ }^{-1} \mathrm{v}^{-1}$. Sen sijaan $0-25 \mathrm{~cm}$ kerroksen P-määrä nousi vuosittain $4.5 \mathrm{~kg} \mathrm{ha}^{-1}$ vailjavuus-P ha ${ }^{-1} \mathrm{v}^{-1}$ eli keskimäärin $20 \%$ taseen ylijäämäfosforista. Fosforia kulkeutui siis myös 0-2 cm kerrosta syvemmälle, vaikka pintamaan pitoisuus nousikin eniten. Jos oletetaan että taseen ylijäämäfosfori jäi 0-25 cm kerrokseen, fosforia sitoutui maahan n. 17-18 kg ha ${ }^{-1} \mathrm{v}^{-1}$ (taulukko $1)$. 


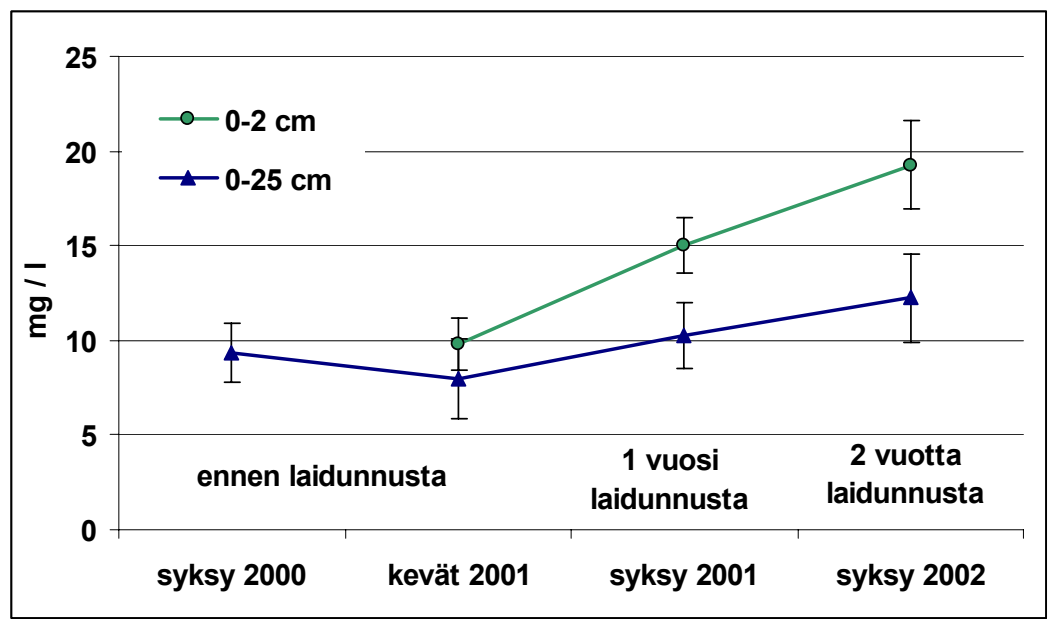

Kuva 1. Maan viljavuus-P pitoisuus mg l-1 0-2ja 0-25 cm syvyydessä ennen laiduntamista sekä 1 ja 2 laidunvuoden jälkeen (Keskiarvo ja keskivirhe $n=6$ ).

Vuotuinen valuma vaihteli $103-222 \mathrm{~mm}$ välillä. Pintavalumaa kokonaisvalumasta oli yli puolet, 61-112 mm, josta n. $90 \%$ tuli lumen sulamisaikaan. Fosfaattifosforia huuhtoutui $0.54-1.13 \mathrm{~kg} \mathrm{ha}^{-1} \mathrm{v}^{-1}$ (kuva 2). Kirjallisuudesta saatuihin arvoihin verrattuna liukoisen fosforin osuus kokonaisfosforista oli korkea, $86 \%$. Suurimmat $\mathrm{PO}_{4}-\mathrm{P}$ pitoisuudet 3.2-4.2 $\mathrm{mg} \mathrm{l}^{-1}$ mitattiin vuosittain heti kevätvaluman alkuun, jonka jälkeen

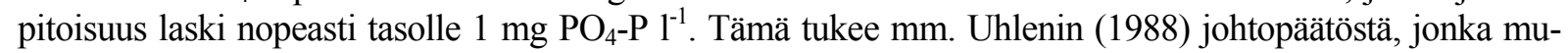
kaan fosforia vapautuu kasvijätteen soluista talven sulamis-jäätymissyklien aikana. Partikkelifosforin keskimääräinen osuus kokonaisfosforista oli vain $12 \%$. Alhainen osuus oli odotettavissakin, koska koealueena oli nurmipeitteinen, helposti läpäisevä mineraalimaa.

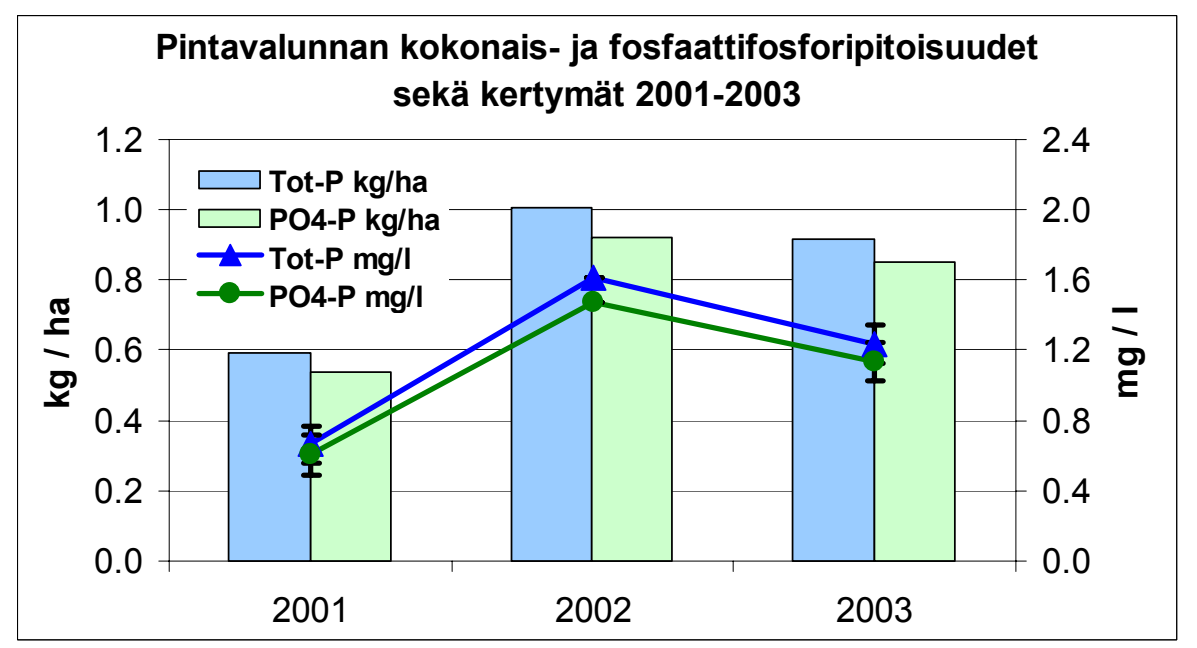

Kuva 2. Laitumelta 2001-2003 tulleen pintavaluman kokonais-P ja $\mathrm{PO}_{4}-\mathrm{P}-$ pitoisuudet $\mathrm{mg} \mathrm{l}^{-1}$ sekä määrät $\mathrm{kg} \mathrm{ha}{ }^{-1}$.

Laitumelta tulevan P-kuormituksen vaikutus järviekosysteemiin riippuu monista tekijöistä. Tärkeimpiä ovat mm. järven tilavuus, pinta-ala ja veden vaihtuvuus, valuma-alueen pinnanmuodot sekä laitumen määrä valuma-alueella. Koska laitumen P-kuormitus on pääosin liukoisessa muodossa, se on hyvin käyttökelpoista leväkasvustoille. Jo $10 \mu \mathrm{g} 1^{-1}$ kokonaisfosforipitoisuuden nousu järvivedessä voi aiheuttaa rehevöitymistä (Sharpley and Smith 1989).

Valuma-alueella sijaitsevan laitumen määrän vaikutusta eri kokoisten järvien rehevöitymisriskiin on arvioitu Vollenweiderin (1975) mallilla (kuva 3). Laskennassa on käytetty järvivedelle 0.85 vuoden viipymäaikaa, joka on keskimääräinen viipymä suomalaisissa järvissä. Malli on staattinen, eikä sitä voi yksinään käyttää järven rehevöitymisriskiä arvioitaessa, koska järveen tulee aina myös muuta Pkuormitusta, jota tämä malli ei huomioi. Malli on kuitenkin käyttökelpoinen työkalu arvioitaessa nimenomaan laiduntamisen vaikutusta järven rehevöitymiseen. Mitä pienempi vastaanottava vesistö on, sitä herkempi se on rehevöitymään. Mallin mukaan pinta-alaltaan 10 ha järvi kestäisi alle 10 ha laitumen suoran 
kuormituksen (olettaen, että valuma-alueella ei ole muita kuormittajia), kun taas 1 ha kokoisen lammen valuma-aluetta ei tulisi käyttää intensiiviseen laiduntamiseen juuri ollenkaan.

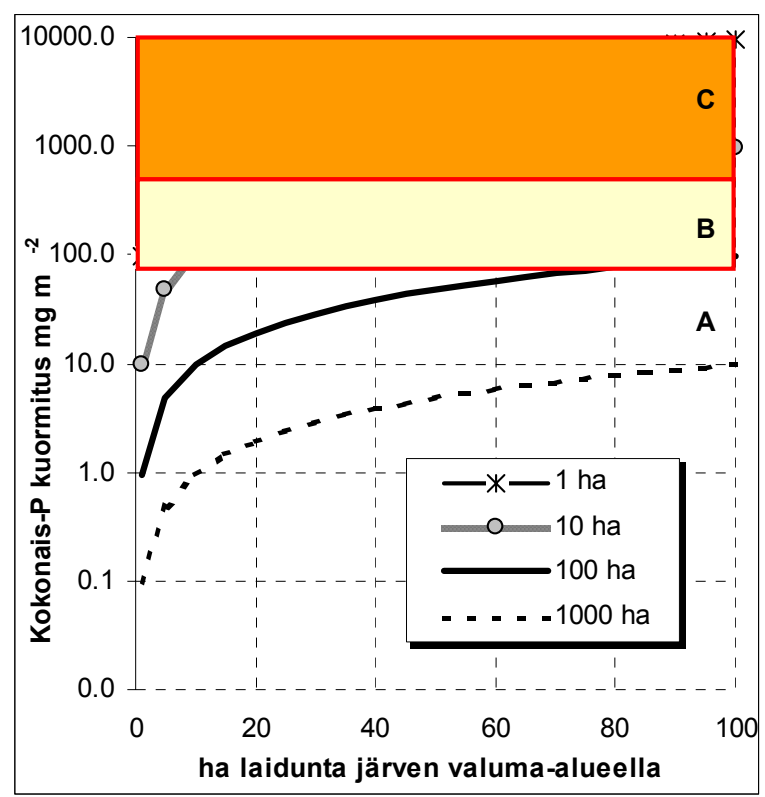

Kuva 3. Järveä ympäröivän laitumen P-valuman vaikutus 1, 10, 100 and 1000 hai kokoisten järvien rehevöitymisriskiin. A-tason rehevöitymisriski on alhainen, B-tason riski on kohtuullinen, mutta riippuu järven ominaisuuksista, Ctason rehevöitymisriski on korkea (Vollenweider1975). Käyrät on laskettu käyttäen 0.85 vuoden viipymäaikaa.

\section{Johtopäätökset ja käytännön sovellukset fosforikuormituksen vähentämiseksi}

Suurin osa pintavalunnasta tulee hietamaalla keväällä. Vaikka laitumen P-huuhtouma on lähes sama kuin muunkin maatalousmaan, liukoisen fosforin pitoisuus on nurmiviljelyssä ja erityisesti laitumella selvästi muita viljelymuotoja korkeampi. Koska liukoinen $\mathrm{P}$ on melko suoraan leville käyttökelpoista, tämä saattaa tietyissä olosuhteissa aiheuttaa järvien rehevöitymistä.

Vesiensuojelussa yleisesti käytetyt suojakaistat ja -vyöhykkeet poistavat tehokkaasti partikkeleihin sitoutunutta fosforia, mutta ovat heikompia liukoisen fosforin vähentämisessä. Laitumien keväistä P-huuhtoumaa voisi olla mahdollista vähentää niittämällä nurmi myöhään syksyllä, kun kasvit ovat sopeutuneet talvehtimiseen. Toinen keino ehkäistä laitumien aiheuttamaa P-kuormitusta, on välttää vesistöön viettävien rantalohkojen intensiivistä laiduntamista. Mitä pienempi ja suljetumpi vastaanottava vesistö on, sitä herkempi se on rehevöitymään.

\section{Kirjallisuus}

Sharpley, A.N. and Smith, S.J. 1989. Prediction of soluble phosphorus transport in agricultural runoff. J. of Env. Qual. 18:313-316

Turtola, E. and Kemppainen, E. 1998. Nitrogen and phosphorus losses in surface runoff and drainage water after application of slurry and mineral fertilizer to perennial grass ley. Agric. and Food Sci. in Finl. 7: 569-581

Turtola, E. 1999. Phosphorus in surface runoff and drainage water affected by cultivation practises. Dissertation. Agricultural Reserch Centre of Finland. Institute of Crop and Soil Science. 108 p.

Uhlen, G., 1988. Surface runoff losses of phosphorus and other nutrient elements from fertilized grassland. Norw. J. of Agric. Sci., 3:47-55

Vollenweider, R.A. 1975. Input-output models. With special reference to the phosphorus loading concept in limnology. Schweiz. Z. Hydrol. 37:53-84. 